SHARON RYAN

\title{
THE EPISTEMIC VIRTUES OF CONSISTENCY
}

\begin{abstract}
The lottery paradox has been discussed widely. The standard solution to the lottery paradox is that a ticket holder is justified in believing each ticket will lose but the ticket holder is also justified in believing not all of the tickets will lose. If the standard solution is true, then we get the paradoxical result that it is possible for a person to have a justified set of beliefs that she knows is inconsistent. In this paper, I argue that the best solution to the paradox is that a ticket holder is not justified in believing any of the tickets are losers. My solution avoids the paradoxical result of the standard solution. The solution I defend has been hastily rejected by other philosophers because it appears to lead to skepticism. I defend my solution from the threat of skepticism and give two arguments in favor of my conclusion that the ticket holder in the original lottery case is not justifed in believing that his ticket will lose.
\end{abstract}

Recently, there has been a lot of commotion about whether or not a person could be epistemically justified in believing a set of statements that she knows is inconsistent. ' Richard Foley, Peter Klein, and Henry Kyburg have each given arguments that seem to show that one can be epistemically justified in believing each member of a set of statements that is known by her to be inconsistent. ${ }^{2}$

That's an extremely important, yet disturbing conclusion. Many of us think that being consistent is an epistemic virtue. With the exception of Gilbert Harman's negative coherence theory of justification, all coherence theories are committed to the claim that coherence is at least a necessary condition for epistemic justification. Many foundationalists have explicitly made commitments to the assumption that consistency is a necessary condition for justification. ${ }^{3}$ It seems that at least part of what makes a belief or set of beliefs justified is that it fits together with one's other justified beliefs. If you know a set of your beliefs is inconsistent, you know you've made a mistake. To continue believing in the face of this known inconsistency seems only to add to your epistemic troubles.

If Foley, Klein, and Kyburg are correct, many of us will be forced to give up a strongly held and seemingly quite plausible assumption about the virtues of believing consistently. Their arguments rest on their answers to the Preface Paradox and an epistemic version of the Lottery Paradox. In this paper, I will examine a purely epistemic version of the Lottery

Synthese 109: 121-i41, 1996.

(C) 1996 Kluwer Academic Publishers. Printed in the Netherlands. 
Paradox and argue that the best solution to that paradox does not show that it is sometimes epistemically rational, to the degree required to satisfy the justification condition for knowledge, for a person to believe each member of a set of statements that is known by that person to be inconsistent. ${ }^{4}$ The lottery paradox has been widely discussed. Some coherentists have already attempted to show that there are versions of coherentism that can escape the lottery paradox. ${ }^{5}$ The arguments I will present are entirely independent of any coherentist assumptions about the nature of epistemic justification.

The lottery paradox is generated by applying the following epistemic principles to a story about Monty, a ticket holder in a fair, one million ticket lottery with one and only one winning ticket.

\section{THE CLOSURE OF JUSTIFIED BELIEF PRINCIPLE:}

(CJBP) If $S$ is justified in believing $p$ at $t$ and $S$ is justified at $t$ in believing $p$ entails $q$, then $S$ is justified in believing $q$ at $t$.

\section{THE NO KNOWN CONTRADICTIONS PRINCIPLE:}

(NKCP) No one is ever justified in believing a statement she knows to be of the form $(p \& \sim p)$

\section{THE CONJUNCTION PRINCIPLE:}

(CP) If $S$ is justified in believing $p$ at $t$ and $S$ is justified in believing $q$ at $t$, then $S$ is justified in believing ( $p \& q$ ) at $t$.

As Henry Kyburg tells the story, we are to imagine a fair, one-million ticket lottery, in which one and only one ticket will be drawn as a winner. ${ }^{6}$ The probability of any one ticket winning is only one in a million. So, it seems that it is rational for Monty, a ticket holder who knows the conditions of the lottery, to believe of any ticket, say his own ticket (which we'll call ' $t_{1}$ '), that it will not be the winning ticket. Since it is a fair lottery, each of the tickets has an equally low probability of winning. Like cases ought to be treated alike. So, if it is rational for Monty to believe his own ticket will lose, then it is equally rational for him to believe his neighbor's ticket (which we'll call ' $t_{2}$ ') will lose too. In fact, for each ticket in the lottery, it seems rational for Monty to believe it will not win since the probability of it winning is only one in a million. Thus, it seems that Monty is justified in believing $t_{1}$ will lose and he is also justified in believing $t_{2}$ will lose and also that $t_{3}$ will lose, and so on, all the way to $t_{1,000,000}$. Let me stipulate that $J s$ means, ' $S$ is justified in believing' and $W t_{1}$ means 'ticket one will win'. Formally, Monty's justified beliefs are:

$$
J s \sim W t_{1} \& J s \sim W t_{2} \& \ldots J s \sim W t_{1,000,000}
$$


Applying (CP) to (1) yields the conclusion that the conjunction of all the individually justified beliefs in (1) is justified for Monty. That is, Monty is justified in believing none of the tickets will win the lottery if he is justified in believing each ticket will not win. That is:

$$
J s\left(\sim W t_{1} \& \sim W t_{2} \ldots \& \sim W t_{1,000,000}\right)
$$

However, it is a fair lottery and Monty knows that one and only one ticket will win. So he rationally believes that either $t_{1}$ will win or $t_{2}$ will win or . . $t_{1,000,000}$ will win. That can be formally expressed as follows:

$$
J s\left(W t_{1} \vee W t_{2} \vee \cdots W t_{1,000,000}\right)
$$

The statement that one and only one ticket will win entails that it is not the case that all the tickets will lose. Assume that Monty is aware of this fact. Hence, given (CJBP), it follows that he is justified in believing that it is not the case that $t_{1}$ will lose and $t_{2}$ will lose and so on, to $t_{1,000,000}$. This can be expressed as follows:

$$
J s \sim\left(\sim W t_{1} \& \sim W t_{2} \ldots \& \sim W t_{1,000,000}\right)
$$

One more application of (CP) leads to the result that Monty is justified in believing the conjunction of (2) and (4) which is:

$$
\begin{aligned}
& J s\left[( \sim W t _ { 1 } \& \sim W t _ { 2 } \ldots \& \sim W t _ { 1 , 0 0 0 , 0 0 0 } ) \& \sim \left(\sim W t_{1} \& \sim W t_{2}\right.\right. \\
& \left.\left.\ldots \& \sim W t_{1,000,000}\right)\right]
\end{aligned}
$$

But (5) says that Monty is justified in believing an explicit contradiction. Assuming (NKCP), we know that something has gone wrong somewhere. Either we are believing and using at least one false epistemic principle, or the facts of the case really do not warrant the application of these principles.

Versions of the closure principle have been rejected by some philosophers. I cannot, in this paper, carefully investigate the merits of various versions of the closure principle. Despite the controversy over closure, it is worth pointing out that the version of the closure principle at use in this paradox, (CJBP), makes a modest claim. If a person is justified in believing some claim $p$ and is also justified in believing that some other claim $q$ is entailed by $p$, it seems quite reasonable to think that she would have evidence adequate to justify her belief in $q$. In addition, since (3) and (4) are logically equivalent and Monty knows this, the usual objections to epistemic closure principles do not apply. Furthermore, even if (CJBP), the general principle behind the move from (3) to (4), is false, (3) and (4) are statements Monty is justified in believing. (3) simply says that either $t_{1}$ or 
$t_{2} \ldots$ or $t_{1,000,000}$ will win. (4) says it is not the case that all the tickets will lose. If the closure principle does not get Monty from (3) to (4), his evidence and an understanding of what (3) and (4) mean will certainly get him from (3) to (4) justifiedly.

The No Known Contradictions Principle is difficult, if not impossible, to argue convincingly against. Something of the form $(p \& \sim p)$ is obviously false to anyone who considers such a statement and knows it to have this form. Knowing that the statement is false would defeat any possible evidence a person might have for believing such a claim to be true. Thus, no one is ever epistemically justified in believing anything she knows to be of the form $(p \& \sim p)$.

So, it looks as though we are left with one option; denying the conjunction principle. Yet I find this epistemic version of the conjunction principle intuitively compelling. Certainly, a conjunction principle does not hold for all operators. For example, a conjunction principle concerning desire is clearly false. Marge may have a strong desire at time $t$ to do a fifty minute run. Marge may also have a strong desire at $t$ to have a beer and a good chat with her best friend Amy. Even though Marge has these individual desires, she may have no desire whatsoever to do the conjunction of these activities all at once, at time $t$.

A conjunction principle about probability also seems false. Adding enough conjuncts can render a conjunction of individually probable statements improbable. The more conjuncts you add, the lower the probability of the conjunction.

A conjunction principle about epistemically justified beliefs, however, seems to be true. Unlike probability, justification seems to be preserved and often strengthened when we add new, justified beliefs to our set of beliefs. Imagine that a person $S$ is justified in believing the following list of individual claims: I am in an airport, I see a plane taking off from the runway, I hear a loud noise, The noise I hear is probably a plane, The noise I hear is probably not a giant snoring. Imagine $S$ forms a conjunction of all of the individual claims listed above. It seems reasonable to think that the justification for the conjoined beliefs is no weaker than is the justification for all the individual conjuncts. If anything, justification is strengthened by conjoining this set of individual beliefs. It is not true that the more conjuncts you add, the less justified the set becomes.

So, although a conjunction principle about desires is false, and a conjunction principle about probabilities is false, a conjunction principle about epistemic justification seems true. Apart from the fact that it, along with the other principles and the lottery story, generates a paradox, this appears to be an innocent epistemic principle. 
It is worth noting that Kyburg introduced the lottery paradox as a puzzle about probability and the rules of rational acceptance. ${ }^{7}$ I am considering whether an epistemic version of the paradox justifies the claim that a person can satisfy the justification condition for knowledge when believing a set of statements she or he knows to be inconsistent. Kyburg is not interested in the epistemic version of the lottery paradox. Although Klein and Foley do not make clear that Kyburg's paradox is about a different topic, they use Kyburg's lottery paradox to draw their epistemic conclusions. Klein and Foley certainly are interested in an epistemic version of the puzzle and clearly believe that consistency is not a necessary condition for epistemic justification.

Despite the initial plausibility of the conjunction principle, in the absence of any better solution to the lottery paradox, (CP) ought to be rejected. We cannot accept the conclusion that a person is justified in believing something he or she knows to be of the form $(p \& \sim p)$. We can deny the conjunction principle and still believe that, for the most part, when a person is justified in believing some statement ' $p$ ' and she is also justified in believing some statement ' $q$ ', she is justified in believing the conjunction ' $p$ and $q$ '. Perhaps it is just in this paradoxical case that conjunction fails.

Several philosophers have come to this conclusion in facing versions of the lottery paradox. The attempted solutions to this paradox, offered by Peter Klein and Richard Foley for example, consist in denying the conjunction principle. Each of them reaches the conclusion that a person, under fair lottery ticket circumstances, is justified in believing, of each ticket, (i) that it is a loser and that (ii) it is not the case that all of the tickets will be losers. With regard to the formal expressions stated above, they accept (1), deny (2), accept (3), accept (4), and deny (5). According to Klein and Foley, what is actually true in the lottery situation is captured formally by the following:

$$
\begin{aligned}
& \left(J s \sim W t_{1} \& J s \sim W t_{2} \ldots J s \sim W t_{1,000,000}\right) \&(J s \sim \\
& \left.\left(\sim W t_{1} \& \sim W t_{2} \& \ldots \sim W t_{1,000,000}\right)\right)
\end{aligned}
$$

Answering the lottery paradox in this way avoids the conclusion that a person could be epistemically rational in believing a set of statements he or she knows to be a contradiction. That's good. However, answering the lottery paradox in this way still supports the conclusion that a person can be rational in believing a set of statements that he or she knows is inconsistent. This is because although one who believes that each ticket will lose and also believes that not all of the tickets will lose is not believing a contradiction, it is still not possible that all of the members in his or her set of beliefs are true. ${ }^{8}$ So, if denying the conjunction principle is the 
best solution to this paradox, we are forced to accept that a person can be epistemically justified in believing a set of statements she knows cannot possibly all be true. That, it seems to me, is still quite paradoxical. That's not so good. It would be good if we had a less paradoxical solution to the lottery paradox.

I think the paradox can be solved in a sensible and modest way that preserves all of the principles that generate the paradox. I think, contrary to first appearances, that as the story was told, (1) is false. I think a person under these lottery conditions is not epistemically justified in believing, of any particular ticket, that it is a loser. Without (1), the conjunction principle is not even applicable.

Unfortunately, taking this position about the lottery looks like it leads straight to the coal pit of skepticism. Before discussing my proposed solution further, it will be worthwhile to address this concern about skepticism. If beliefs about the individual tickets are not justified, then it seems that none of our beliefs are justified. Since it seems sensible to think that at least some of our beliefs are justified, denying (1) seems unreasonable.

Foley, for example, argues that denying (1) leads to skepticism. He claims that the evidence we have for each of the tickets losing is "at least as strong as the evidence we have for the claim that the room we just left still has furniture in it ...". 9 Since believing the room we just left has furniture in it is epistemically justified so is believing our lottery ticket will lose. If Foley is correct, then my solution is just as bad as, if not worse than, solutions that deny the conjunction principle. At least denying the conjunction principle accords with the facts about desires and probability. In addition, there are issues about probability that at least seem relevant to this paradox. So, it might be better to avoid skepticism and swallow the conclusion that in these odd lottery paradox cases, the conjunction principle is false and sets of claims that are known by a person to contain a false claim are nevertheless justified for that person.

Foley's argument against denying (1) rests on the assumption that the situation the ticket holder is in is as good as the situation we are in for our ordinary, external world beliefs. Let's think more carefully about the evidence typically had by a person for these ordinary, external world beliefs and the evidence had by a person in this lottery case. Think for a moment about the belief that the furniture will remain in the room after we leave the room. Assume very ordinary conditions for this ordinary, external world belief. Imagine that the room is a room in your own house and no remodeling of the room is scheduled to occur and so on. Under such ordinary conditions, one has no reason whatsoever to think the furniture will leave the room. Under normal conditions, we have strong inductive 
evidence for thinking the furniture will stay in the room as it has without failure in the past. All this evidence adds up to justify us in believing that the furniture will remain in the room after we leave it. Thinking that the furniture will not remain in the room, despite all the good evidence to the contrary, certainly does count as a belief that one would typically be unjustified in holding. Suspending judgment about whether or not the furniture will remain in the room would also be irrational. The person's total evidence overwhelmingly supports believing the furniture will remain in the room after she or he leaves.

If we are in equally good standing with lottery tickets as we are with furniture, then Foley is right; denying (1) would be a mistake. However, contrary to immediate appearances, there is an important difference between the furniture case and the lottery, and as a result, we are worse off, with respect to epistemic justification, in the lottery case. In the lottery case, it is true that the probability of a ticket winning is one in a million. It is assumed that Monty knows the probability of his ticket winning is so low. That, by itself, seems like an extremely good reason to believe, of any ticket, that it is a loser. If this were all there were to the story, then Foley would be correct. But, in the lottery case, there is other crucial evidence. Monty knows that there is one and only one winning ticket. Monty can be sure that despite the fact that the chances of any one ticket winning are so low, one ticket will definitely win. Monty has no idea which ticket is the winner because the tickets are indistinguishable in all ways relevant to which ticket will win. His total evidence includes the probabilistic evidence for each ticket winning, but it also includes the fact that one ticket will definitely win. Noticing this counterevidence is crucial for noticing the disanalogy between the lottery case and the furniture case.

In the furniture case we do not have any justified counterevidence. Under any normal circumstances, we have some wild hypotheses that we may or may not think about. There is the possibility of aliens taking it. There is Descartes' evil furniture-stealing demon. There is the dream hypothesis. There is the possibility that the furniture was made with byzantium which will cause the furniture to evaporate into toxic fumes, perhaps seconds after we leave the room. There is the hysterical husband syndrome (h.h.s.) that sometimes leads husbands to throw furniture out of closed, but soon to be broken, windows. All of these possibilities are wild scenarios. These hypotheses may be negatively relevant to believing the furniture will remain in the room, but they are defeated by the rest of one's evidence in this case. Maybe furniture-stealing demons will invade and swipe the furniture but typically one has no reason whatsoever to think they will. If the evidence stays the same, the person definitely ought to believe that the furniture will 
remain in the room. The person's total evidence supports his or her belief about the furniture.

The furniture case is simply not analogous to the lottery. We need to do some serious concocting of the furniture example to make the two cases analogous. Once we do such concocting and make the furniture case analogous to the lottery case, believing the furniture will remain in the room will not be a justified belief. Likewise, if we were to change the conditions of the lottery so the lottery case is like the original, unconcocted version of the furniture case, where the person is justified in believing no ticket will win, then believing one's ticket will lose is justified. In that case, one ought to believe one's own ticket and all the other tickets will lose. But that lottery case is no paradox. We would not have a case of justified, inconsistent beliefs.

It is time for some serious concocting of the furniture case. Consider the following furniture case involving Smith and Jones, a married couple with a big problem. Imagine that Smith, one member of the couple, considers whether the furniture will remain in the room on each of one million times that she leaves the room. Suppose further, that Smith and Jones are having trouble in their marriage. They turn to a psychotherapist to help them save their relationship. Imagine that after years and years of psychotherapy, it is discovered that Jones has the horrible hysterical husband syndrome (h.h.s.). Smith and Jones are warned by the therapist that on one of the next one million days, with absolutely no warning signs, Jones is going to blow his stack. He is going to frantically throw all the furniture out the window. Now, we have a furniture case that is analogous to the lottery case. Like cases ought to be treated alike. We ought to treat this furniture case and the lottery case in exactly the same way. Suppose that Smith and Jones get out a stack of calendars that show the next million days and consider, for each day on the calendar, whether that day is the day that Jones throws the furniture out the window. In this case, I think Smith and Jones are not justified in believing, with respect to each date they consider on the calendar, that this is not the date Jones' condition is going to manifest itself. In this case, Smith does not know the furniture will remain in the room after she leaves it. She fails to know because she fails to satisfy the justification condition for knowledge. Smith and Jones have sufficient reason to worry, doubt, place a "falling furniture zone" sign on their front lawn, and put any valuable pieces of furniture at their friends' houses until the dreadful day has passed. Although it is probable, on each day, that the furniture will not get thrown out the window, it is not epistemically rational to believe, of any date, that the furniture will not be thrown out the window on that date. Sometimes, having probabilistic evidence is not sufficient to 
warrant rational belief. This version of the furniture case and the lottery are paradigm cases.

It is crucial to note that I am not arguing that probabilistic evidence is never sufficient to justify a belief. In the original furniture case, I contended that it was probable that the furniture would stay in the room. In that case, this evidence was sufficient to justify the person in believing that the furniture would stay in the room on each day. It is in the revised case, when the couple is informed that Jones has h.h.s., that I think a probable belief fails to be epistemically rational. In the hysterical husband syndrome case, Smith and Jones are only justified in believing of each date in their stack of calendars, that the furniture will probably stay in the room on that date. Believing that it will stay in the room is not supported by their total evidence.

It is important to keep in mind that the lottery case and the revised furniture case are very odd cases. Mostly, we do not have a bunch of individually well supported beliefs, which are such that we know that one, but not which one, is false. ${ }^{10}$ Often, when we have several reasonable beliefs to choose from and we know one is false, we have good enough reason to reject one belief to the exclusion of the others. When we are in such odd, lottery-like circumstances, it seems correct to think that one is not justified in believing each of the probable, individual beliefs.

Thus, Foley's argument is not successful. Denying (1) does not lead to skepticism about ordinary external world beliefs. Ordinary external world beliefs are not enough like these lottery-like cases. The lottery case is not analogous to Foley's original furniture case. We had to make the furniture case quite crazy in order for it to be analogous to the lottery case. In the revised furniture case, Smith is not justified in believing the furniture will remain in the room. This is not a skeptical position.

I think Foley failed to distinguish two different principles that could motivate one to deny (1). One principle that does lead to skepticism and might be used in attempting to solve the lottery paradox makes use of a certainty requirement. This principle can be stated as follows:

(CR) If $S$ is justified in believing $p$, then the probability of $p$, given $S$ 's total evidence, is 1 .

A skeptic who accepted (CR) would claim to solve the lottery paradox by pointing out that the statement ' $t_{1}$ will lose' has a probability of 0.999999 . That's just short of 1 . So, although one is almost justified in believing ' $t_{1}$ will lose', the person's evidence is not good enough to reach the level required for justification. Hence, one holding (CR) would claim, as I have claimed, that (1) is false. (CR) is much too strict because it does rule out 
almost all of the examples we would think of as instances of justified beliefs. Adherence to (CR) would lead one to think that one is not justified, under ordinary circumstances, in believing that one's furniture will not leave one's room. If the only reason for denying (1) were because one accepted (CR), Foley's argument would be quite good. Then we would be forced back to denying the conjunction principle and accepting the conclusion that believing a set of statements you know is inconsistent is sometimes epistemically rational.

The principle that lead me to deny (1) is very different from (CR). The principle I am appealing to does not require that one's beliefs be certain. The principle I have in mind captures the odd distribution of the evidence in lottery-like cases. It seems that what goes wrong in the lottery case is not that Monty does not have enough evidence to believe that his ticket is a loser but that he is in a peculiar situation of knowing one of his beliefs is false but not having any idea which belief is false. I was appealing to the following principle which I will call the Avoid Falsity Principle:

\section{AVOID FALSITY PRINCIPLE:}

(AFP) For any set $L$ of competing statements, if (i) a person $S$ has good reason to believe each member of $L$ is true and (ii) either $S$ has good reason to believe at least one member of $L$ is false or $S$ is justified in suspending judgment about whether at least one member of $L$ is false, then $S$ is not epistemically justified in believing any of the competing individual members of $L$.

(AFP) needs some explanation. By 'competing statements', I mean all the statements that are individually reasonable but are called into question with the introduction of reasonable counterevidence. For example, suppose a book you were reading just five minutes ago is missing from your office. You suspect that either Ned or Mark, your two colleagues who were in your office during the past five minutes, has borrowed your book. You ask each of them if he took your book and each one denies taking the book. Suppose you have good reason to believe Ned and Mark are both reliable and honest. At this point, it seems rational for you to believe Ned and Mark and look around your office a bit more and consider whether anyone else has been in your office in the past five minutes. Your total set of beliefs at this point includes an enormous amount of beliefs. Suppose that among your entire set are such beliefs as: 'Michael Jordan is a great basketball player', 'George Washington was the first President of the United States', 'Space aliens regularly visit the earth', 'Mark did not take my book', and 'Ned did not take my book.' Now suppose that after a thorough investigation of 
the book mystery, you somehow determine for certain that either Mark or Ned took the book from your office. This justified counterevidence turns a subset of your total set of beliefs into a competing set of beliefs. The subset that includes 'Ned did not take my book' and 'Mark did not take my book' is a competing set of beliefs. Since you now have excellent reason to believe either Mark or Ned took your book, those two beliefs are in competition. One of them has to be false given your total evidence. Your beliefs about Michael Jordan, George Washington, and the space aliens are not competing with your beliefs concerning Mark or Ned taking the book. Your belief about Michael Jordan, for example, falls outside the set of competing statements since the fact that either Ned or Mark took the book has no bearing on your belief about Michael Jordan. With respect to the lottery, Monty's beliefs including, ' $t_{1}$ will lose', ' $t_{2}$ will lose', and so on to ' $t_{1,000,000}$ will lose' are in competition as a result of his reasonable belief that 'one ticket will win'. However, suppose that within Monty's entire set of beliefs is the statement, 'I exist'. Under such conditions, 'I exist' is not in competition with any of the individual lottery beliefs. The counterevidence, that one ticket will win has no bearing whatsoever on the truth of 'I exist'. S ought to retain 'I exist' upon the introduction of this counterevidence. In addition, other beliefs relevant to the lottery, but not competing with 'ticket one will lose' and so on to 'ticket one million will lose' are not ruled out by (AFP). For example, 'some ticket will win', may be a member of $S$ 's total set of beliefs, but it is not one of the beliefs called into question and competing for truth due to the counterevidence. In fact, the counterevidence supports 'some ticket will win'. So, one is still justified in believing some ticket will win.

By 'good reason to believe $p$ ', I mean the following:

$S$ has good reason to believe $p$ iff $S$ 's total evidence supports $p$ more than it supports $\sim p$.

By ' $S$ is justified in suspending judgment about $p$ ', I mean the following:

$S$ is justified in suspending judgment about $p$ iff $S$ is not justified in believing $p$ and $S$ is not justified in believing $\sim p$.

It is important to note that having good reason to believe is not equivalent to being justified to the degree required for knowledge. It is possible to have good reason to believe a claim that you are not justified in believing to the degree required for knowledge. This is because it is possible to have good reason to believe a claim when your evidence only slightly supports it over its negation. However, anytime one is justified in believing a claim to the degree required for knowledge, that person has good reason to believe 
that claim. So, with respect to the lottery beliefs, Monty has good reason to believe his ticket will lose because Monty's total evidence supports believing his ticket will lose more than it supports believing his ticket will not lose. Likewise, he has good reason to believe one of the tickets will win because his total evidence supports believing that more than his total evidence supports believing it is not the case that one ticket will win. It is also important to note that having good reason to believe $p$ and being justified in suspending judgment about $p$ are not exclusive concepts. A person may have good reason to believe some claim because her evidence slightly favors believing the claim is true. In such a case, she would not have enough evidence to be justified in believing $p$. So, although she would have good reason to believe $p$, she is justified in suspending her judgment about $p$.

Applying (AFP) to the lottery situation rules out the possibility of the individual beliefs stated in (1) being justified for Monty. That is, according to (AFP) and the facts of the lottery, Monty is not justified in believing any of the individual tickets will lose. Monty has a competing set of beliefs. The set that includes: 'Ticket one will lose', 'ticket two will lose', ... 'ticket one million will lose'. The counterevidence Monty has, namely that one ticket will win, constitutes good reason to believe one member of the set of competing statements, $\left(\sim W t_{1}, \sim W t_{2}, \ldots \sim W t_{1,000,000}\right)$ is false. Yet, Monty does have good reason to believe each of the individual statements. Monty does have good reason to believe, of each ticket, that it will lose. Thus, according to (AFP), Monty is not epistemically justified in believing, of any individual ticket, that it is a loser.

In addition, (AFP) rules out the individual furniture beliefs in the revised furniture case. The competing set of beliefs includes such beliefs as 'the furniture will remain in the room on January 1, 1997', 'the furniture will remain in the room on January 2, 1997', and so on. In the revised furniture case, Smith and Jones have good reason to think the furniture will not be in the room on one of the one million days. Yet, they have good reason to believe, with respect to each day, that that day is a day where the furniture will remain in the room. (AFP) yields the result that Smith and Jones are not justified in believing, with respect to any individual day, that that day is a day where the furniture will remain in the room. (AFP) does not give this result in the original furniture case, where one would be justified in believing the furniture will remain in the room. That's good.

(AFP) also handles other versions of the lottery. Consider some other ways things could go. Consider an lottery with one million tickets where there will definitely be a winner but you know that not all the tickets have the same probability of winning. Imagine, for example, that you know that 
the fifty blue tickets sold have a much higher probability of winning than all the rest of the tickets. In that case, the relevant set of competing claims is restricted to the beliefs concerning the blue tickets. And, those are the beliefs (AFP) tells you to suspend your judgment about. In such cases, one could be justified in believing some of the tickets are losers yet not be justified in believing others are losers.

Consider a lottery with a guaranteed winner where the probabilities are unequal but the ticket holder is ignorant that the probabilities are unequal. Suppose the ticket holder thinks he is in a fair lottery with one million tickets where one and only one ticket will win. In that case, given the ticket holder's evidence, each of the individual lottery beliefs is a member of the competing set of beliefs. In that case, despite the fact that the probabilities are actually unequal, the ticket holder is not justified in believing any individual ticket will lose. This is good since given the ticket holder's evidence, this lottery is just like the original lottery. (AFP) still yields the result that the ticket hold is not justified in believing any of tickets is a loser.

(AFP) also handles other apparently paradoxical lotteries in which one does not have a good reason to believe there is a winner. Imagine a fair lottery with one million tickets and one and only one winner if a ticket is drawn. Suppose that whether or not there is a winner drawn depends on the whim of the Mayor. On some days he decides to run the lottery drawing and on other days he decides to ignore the lottery. Suppose that on 50\% of the days a winning ticket is drawn and on $50 \%$ of the days the Mayor goes jogging instead of picking a winning lottery ticket. Consider a ticket holder who knows that there is only a $50 \%$ chance that any ticket will be drawn as a winner. In such a case, it is clearly not true that the person would be justified in believing all of the tickets are losers; that is something he should be suspending judgment about since it depends on the whims of the mayor. Yet, it does seem that with respect to each ticket, the person is justified in believing it is a loser. It looks like we have another paradox on our hands. We seem to have a case where a ticket holder would be justified in believing each ticket is a loser yet not justified in believing all of the tickets are losers. (AFP) has an answer. In such a case, the ticket holder is justified in suspending judgment about whether one of the competing lottery beliefs is false. (AFP) implies that one is not epistemically justified in believing any of the individual lottery beliefs. So, (AFP) nicely avoids this version of the lottery paradox as well.

We can change the conditions of the lottery and say the ticket holder knows that the Mayor draws a lottery ticket $49 \%$ of the time and fails to draw a lottery ticket $51 \%$ of the time. In this case, the ticket holder has 
slightly better reason to believe a ticket will not be drawn. In this case we would get the same result as in the previous case. In this case, it is still true that the ticket holder is not justified in believing there will be a winner. Whether a ticket will be drawn is still within the range of suspending judgment. So, the ticket holder ought to suspend judgment on the claim that one of the tickets is a winner. The ticket holder has good reason to believe each of the individual lottery tickets will lose, but the ticket holder is justified in suspending judgment about whether all of the individual lottery tickets are losers. So, (AFP) implies that the ticket holder is not justified in believing his ticket, and each of the other tickets, is a loser. This will be true for all similar lotteries where the person is in a situation that falls within the range of cases where she or he would be epistemically justified in suspending judgment about whether there will be a winner. Once we get away from that range of cases and move to the range where the person is justified in believing there will not be a winner, we move away from the range of paradoxical cases. So, (AFP) seems able to handle the full range of paradoxical cases.

Although (AFP) seems able to handle the full range of paradoxical cases and does not lead to skepticism, Jonathan Vogel has suggested that a principle very much like it leads to semi-skepticism. ${ }^{11}$ That is, it leads us to be skeptical about many, but not most, of our beliefs. If (AFP) leads to semi-skepticism, then we have another argument against denying (1) as the best solution to the lottery paradox. Consider Vogel's example:

In effect, when you park your car in an area with an appreciable rate of auto theft, you enter a lottery in which cars are picked, essentially at random, to be stolen and driven away. Having your car stolen is the unfortunate counterpart to winning the lottery. And, just as one doesn't know that one's number won't come up in the lottery, it seems that one doesn't know that one's number won't come up, so to speak, for car theft. ${ }^{12}$

In this case you are to assume that it is very likely that some car like your car, in all the relevant ways, will be stolen. However, most cars like your car in all the relevant ways will not be stolen. Since the probability of your car actually being one of the stolen cars is so low it seems rational to believe that it is not the case that your car will be stolen. Since you have no reason to discriminate, you should believe this of each of the cars like your car. But, if the conjunction principle is true, you should believe that all cars like your own will not be stolen. But that is in contradiction to the initial assumption that some car like your own car will be stolen. We seem to have another lottery case.

If this is analogous to the original lottery case, then I should be consistent and answer Vogel's car lottery in the way I answered the original lottery case. If I answer this case in the way I answered the original lottery case, 
I will appeal to (AFP) and conclude that people under such conditions really are not justified in believing that their car has not been stolen. That looks bad for my view since it seems to show that we are never justified in believing our cars have not been stolen. Common sense tells us that most of us really are justified in thinking our cars have not been stolen.

As interesting as the comparison is between car theft and lotteries, I think the similarities between the two are not so close as Vogel suggests. It seems to me that beliefs about losing the lottery are importantly different from beliefs about whether one's car has been stolen. In the lottery one is definitely justified in believing there will be a winner. In the car case it is much less clear that the person is justified in believing a car in all relevant ways like one's own car will be stolen. An important question which is left open by Vogel's case is what the relevant respects are. The relevant respects about one's car being stolen should include facts about the neighborhood you park in, the street you park on, the time of day, the type of car you drive, whether you locked the car, whether you have one of those anti-theft bars on the steering wheel, and so on. Typically, many of us have no good reason to think any car similar to ours in the relevant respects just mentioned will be stolen. We think some car in our town will be stolen at some point, but we usually have no good reason to believe a car just like ours, in all the relevant respects will be stolen. So, under ordinary circumstances, we ought to think all cars similar to ours in the relevant ways will not be stolen. There is no paradox under such "normal" conditions and no need to appeal to (AFP) under ordinary circumstances.

Of course, we could construct a case in which one does have good reason to believe or is justified in suspending judgment on the claim that some car in all relevant ways like one's own will be stolen. Imagine that you hear on the radio in your office that a car has been stolen from your street. Imagine that in all relevant respects, you have a typical car for that street. In such a case, you would have no good reason to rule out some cars over the others. You would be justified in believing that some car in all the relevant ways like your own car was stolen. The chances of your car actually being the "winner" is low. If probability were all there is to rationality, then you would be justified in believing that your car and each of the neighbor's cars were not stolen. However, it seems that given that you know some car just like yours has been stolen and you have no reason to rule your car out as the unlucky draw, you really have insufficient grounds for believing your car was not stolen. Again, typically we are not in such circumstances. Typically, we have grounds on which to discriminate. In this rather odd case, (AFP) tells us that you are really not justified in believing the individual beliefs about one's car not being 
stolen and all similar cars not being stolen. The best you can believe is that it's probably not your car that was stolen. Intuitively, that's how things should be. People who live in car theft neighborhoods with cars that thieves want are, in fact, not confident that their car will not be stolen. One is not epistemically justified, under such circumstances, in believing one's car has not been stolen. Thus, (AFP) guides us to be rational, but not skeptical. Most of us are not in lottery-like situations with respect to our car being stolen. Those who really are in lottery-like conditions would be rational, rather than skeptical, if they failed to believe that their car has not been stolen.

Cases where a person is really justified in suspending judgment about whether a car like their car has been stolen should be treated just like the cases where they actually have good reason to think a car just like their car was stolen. That is exactly how (AFP) tells us to treat the cases. Imagine that you park in a parking lot with one hundred cars where a car just like yours is stolen $50 \%$ of the time. In such a case, you are justified in suspending judgment about whether a car like yours has been stolen from your parking lot. In that case, despite the fact that the probability of your car being stolen is quite low, you are not justified in believing your car has not been stolen. I suspect that anyone in such a situation would not believe their car has not been stolen. I would say such a person ought to be considered rational and not skeptical. I would also say that this is not a situation in which many of us find ourselves.

It seems that there is afterall no threat of skepticism in denying (1). I wish to turn now to consider some positive arguments for denying (1). My first argument for denying (1) rests on an assumption skeptics, anti-skeptics, internalists, externalists, coherentists and foundationalists all share. According to the paradox, Monty believes his ticket will lose. Suppose that Monty's ticket will actually be a loser. That's not at all hard to imagine. Do you think Monty's belief satisfies the conditions for knowledge? Almost everyone has the intuition that Monty does not know his ticket is a loser even if his ticket actually is a loser. The lottery paradox is not a "Gettier Case". That is, it is not a case in which a person has defective or misleading evidence for a justified, true belief, that is not knowledge. Since this is not a Gettier case, if we assume Monty's ticket will lose and assume that Monty satisfies the belief condition, the only option open to explain why Monty's belief fails to be an instance of knowledge is that it fails to satisfy the justification condition for knowledge. I will call this argument the "What Else Could it Be?" argument. 


\section{WHAT ELSE COULD IT BE?}

(1) Monty does not know that his ticket will lose.

(2) The lottery paradox is not a Gettier Case.

(3) If Monty does not know that his ticket will lose and the lottery paradox is not a Gettier Case, then either Monty does not believe his ticket will lose or it is not true that his ticket will lose or Monty is not justified in believing his ticket will lose.

(4) Either Monty does not believe his ticket will lose or it is not true that his ticket will lose or Monty is not justified in believing his ticket will lose. (1), (2), (3)

(5) Monty's ticket will lose and he believes his ticket will lose.

(6) Monty is not justified in believing his ticket will lose. (4), (5)

The "What Else Could it Be?" argument is valid and I think the premises should be acceptable to anyone. So, I think those who deny the conclusion, in light of this argument, are doing so unreasonably. It is worth mentioning that on one account of the fourth condition for knowledge, the lottery is a Gettier case. Roderick Chisholm proposed an analysis of knowledge that would imply that the lottery beliefs are not knowledge because they fail to satisfy the fourth condition. ${ }^{13}$ Chisholm's fourth condition was basically that the evidence a person has for a belief that is known cannot justify any falsehood for that person. With respect to Gettier's example, this account implies that 'Jones owns a Ford or Brown is in Barcelona' is a justified, true belief but not knowledge because the evidence Smith has for this belief justifies the false belief that 'Jones owns a Ford'. Anyone who accepted a view along these lines could object to premise (2) of my argument. Monty's belief that his ticket will lose would be a justified, true belief but not knowledge because it fails to satisfy the fourth condition. The evidence Monty has for this belief justifies him in believing of each of the other tickets that it will lose. But since one ticket will win, his evidence does justify one falsehood. However, this response to my argument is not reasonable since this analysis of knowledge is implausible.

We can see that the proposed analysis of knowledge is false by considering Monty's situation. Let's grant for the sake of the argument that Monty's belief that his ticket will lose is a justified, true belief. Consider 
Monty's belief that the probability that his ticket will lose is 0.999999 . In the conditions of this case Monty knows that the probability of his ticket losing is 0.999999 . However, the evidence he has for this belief is the same evidence that is supposed to justify him in believing the false claim that ticket $n$ will lose where $n$ happens to be the winning ticket. If Chisholm's account is accepted, we can grant that Monty's belief that his ticket will lose is justified but not a case of knowledge, but we are forced to deny that he knows that the probability of his ticket losing is 0.999999 . Monty surely knows that the probability of his ticket losing is 0.999999 . So, Chisholm's account ought to be rejected. I know of no other analysis of knowledge that is plausible and implies that Monty's belief is justified but not knowledge. So, I see no good reason to reject premise (2). If Monty does not have knowledge about any particular ticket losing it is not because his belief is justified yet does not satisfy the fourth condition for knowledge. It is because it is false or because it is not justified. Since we are stipulating that his belief is true, we can be sure that his belief is not justified.

Contrary to initial appearances, although Monty is justified in believing his ticket will probably lose, he is not justified in believing his ticket, or anyone else's ticket, will lose. Claiming that Monty is not justified in believing his ticket, or anyone else's ticket is a loser gives us a solution that actually accords with intuitions almost all of us share. Monty does not know his ticket is a loser because he is not justified in believing his ticket is a loser. Monty's belief is unjustified because the attitude of belief fails to fit his evidence. It is not because he does not have enough evidence. It is not the amount of the evidence that matters in this situation, but the way the evidence is so oddly distributed in lottery-like cases.

I have a second argument in support of my view on the lottery paradox. The argument is that if we assume that Monty is justified in believing that each of the tickets will lose, we will be led to conclude that Monty knows that some arbitrary ticket will be the winner. However, by hypothesis, Monty has no reason whatsoever for believing, of any particular ticket, that it will be the winner. So, it can't be true that Monty is justified in believing, of each of the individual tickets in the lottery, that it is a winner. ${ }^{14}$ The argument, which I shall name the "Don't Believe You're a Loser" argument can be explicitly stated as follows:

(1) $J s\left(\sim W t_{1}\right) \& \ldots J s\left(\sim W t_{2}\right) \& J s\left(\sim W t_{1,000,000}\right)$ (assumption for reductio)

(2) $J s\left(W t_{1} \vee W t_{2} \vee \ldots W t_{1,000,000)}\right.$ (stipulated fact about the lottery) 
(3) $J s\left(\sim W t_{1}\right)$ (1), (simplification)

(4) $J s\left(\sim W t_{2}\right)$ (1), (simplification)

(n) $J s\left(\sim W t_{999,999)}(1),(\right.$ simplification)
$(n+1) J s\left(W t_{1,000,000}\right)(2)-(n)$, (epistemic version of disjunctive syllo- gism)
$(n+2) J s\left(\sim W t_{1,000,000}\right)(1)$, (simplification)
$(n+3)$ If $J s\left(\sim W t_{1,000,000}\right)$ then $\sim J s\left(W t_{1,000,000}\right)$

$(n+4) \sim J s\left(W t_{1,000,000}\right)(n+2),(n+3)$

(c) $\sim\left[J s\left(\sim W t_{1}\right) \& J s\left(\sim W t_{2}\right) \& \ldots J s\left(\sim W t_{1,000,000}\right)\right]$ (reductio ad absurdum $),(n+1),(n+4)$

So, as the "Don't Believe You're A Loser" argument proves, one is not justified in believing one's ticket is a loser when he or she enters a fair, one million ticket lottery. Premise (1) leads to the conclusion that one is justified in believing a particular ticket is the winner. But that is absurd. A fact about the case is that the person is not justified in believing any particular ticket is the winner. The tickets are indistinguishable with respect to which ticket will win. This argument shows that even if we deny the conjunction principle, we will be led to a paradox.

Again, I believe I have stated a valid argument with reasonable premises that leads to the conclusion that it is not the case that Monty is justified in believing, of each ticket, that it will not win. The only features of this argument not explicitly granted by my opponents is my use of the epistemic version of disjunctive syllogism and the epistemic principle justifying premise $(n+3)$. The epistemic principle backing premise $(n+3)$ is that if a person is justified in believing $p$ is false it follows that they are not justified in believing $p$ is true. This principle seems to me to be uncontroversial and ought to be accepted by anybody. Perhaps those who deny the epistemic conjunction principle would deny the epistemic disjunction principle. ${ }^{15} \mathrm{I}$ cannot see any reason to deny an epistemic disjunction principle. I believe my opponents ought to accept an epistemic disjunction principle. If a person is justified in believing that either $p$ is true or $q$ is true and she is 
justified in believing $q$ is false, she has excellent reason to believe $p$ is true. Furthermore, in light of my "What Else Could It Be?" argument, it seems far more reasonable to give up on the claim that Monty's beliefs are justified than it is to give up on the epistemic disjunction principle. If my opponent's case rests on giving up conjunction, disjunctive syllogism, and the principle that one is never justified in believing a set of statements he or she knows to be inconsistent, without any objections other than the paradox itself, so much the worse for their case.

I have offered a plausible alternative to the standard solutions to the lottery paradox. Contrary to first appearances, my solution does not lead to skepticism or semi-skepticism. My solution accords with several reasonable assumptions. It has the virtue of preserving all the epistemic principles responsible for generating the lottery paradox. It explains the intuition that a ticket holder has a probable belief, but fails to know that his or her ticket is not the winner. In addition, my solution also preserves the strong intuition that it is not possible for a person to be epistemically justified in believing a set of statements that is known by him or her to be inconsistent. ${ }^{16}$

\section{NOTES}

${ }^{1}$ I will be using 'epistemically justified' and 'epistemically rational' interchangeably throughout this paper.

${ }^{2}$ Richard Foley (1992; 1979; 1987, 98-102). Peter D. Klein (1985; 1981, 190-201). Henry Kyburg (1970, 55-82).

${ }^{3}$ For some examples of explicit commitments to consistency among coherentists and foundationalists see Robert Ackermann $(1972,33)$. Laurence Bonjour $(1985,95)$. Roderick Chisholm $(1989,71)$. Keith Lehrer $(1974,202 ; 1990)$. C. I. Lewis $(1946,334)$. John L. Pollock (1983).

${ }^{4}$ It has been argued that the preface paradox is not a genuine instance of a set of epistemically justified, yet known to be inconsistent beliefs. See Sharon Ryan (1991).

${ }_{6}^{5}$ For example, Keith Lehrer argues for this conclusion in (1990).

${ }^{6}$ Kyburg (1970).

${ }^{7}$ Kyburg (1970).

${ }^{8}$ Along with Foley, I'm assuming:

A set of statements $L$ is inconsistent iff it is not possible that all the members of $L$ are true.

${ }^{9}$ Foley $(1987,245)$.

${ }^{10}$ The preface paradox is much less contrived than the lottery paradox and the revised furniture case. However, even the much more ordinary situation envisioned in the preface paradox fails to be a genuine instance of justified, known to be inconsistent beliefs. See Note 4.

${ }^{11}$ Jonathan Vogel (1990).

${ }^{12}$ Vogel $(1990,16)$. 
${ }^{13}$ Roderick Chisholm (1977, 110).

${ }^{14}$ Richard Foley mentioned, and hastily rejected, this argument in "Justified Inconsistent Beliefs" (1991). Foley rejects this argument because he denies that all justified beliefs can be used as premises in arguments. He claims that while the lottery beliefs are justified, they cannot be used as premises. Since Foley claims that the lottery beliefs are at least as justified as other ordinary external beliefs, he will be forced either to deny that most of our beliefs can be used as premises in arguments or to provide some special reason for treating the lottery claims differently.

${ }^{15}$ I am grateful to Peter Klein for an interesting and lively debate about this topic.

${ }^{16}$ I am grateful to Mark Aronszajn, Earl Conee, Theodore Drange, Mylan Engel, Richard Feldman, Peter Klein, Virginia Klenk, Keith Lehrer, Jee-Loo Liu, Ned Markosian, Michael Roth, Bruce Russell, Lenhart Schubert, Amy Steinberg, and Edward Wierenga and two anonymous referees from Synthese for helpful comments on previous drafts of this paper.

\section{REFERENCES}

Ackerman, R.: 1972, Belief and Knowledge, Doubleday \& Co., New York.

Bonjour, L.: 1985, The Strucutre of Empirical Knowledge, Harvard University Press, Cambridge, MA.

Chisholm, R.: 1989, Theory of Knowledge, 3rd. Ed., Prentice Hall, Englewood Cliffs, NJ.

Foley, R.: 1979, 'Justified Inconsistent Beliefs', American Philosophical Quarterly 16, 247-57.

Foley, R.: 1987, The Theory of Epistemic Rationality, Harvard University Press, Cambridge, MA.

$\rightarrow$ Foley, R.: 1992, 'The Epistemology of Belief and Epistemology of Degrees of Belief', American Philosophical Quarterly 29, 111-24.

Klein, P.: 1981, Certainty: A Refutation of Scepticism, University of Minneapolis, Minneaplois, $\mathrm{MI}$.

Klein, P.: 1985, 'The Virtues of Inconsistency', The Monist 68 105-35.

Kyburg, H.: 1970, 'Conjunctivitus', in Marshall Swain (ed.), Induction, Acceptance and Rational Belief, D. Reidel, Dordrecht, pp. 55-82.

Lehrer, K.: 1974, Knowledge, Oxford University Press, Oxford.

Lehrer, K.: 1990, 'Reason and Consistency', in his Metamind, Clarendon Press, Oxford, pp. 148-166.

Lewis, C. I.: 1946, An Analysis of Knowledge and Valuation, Open Court Publishing, La Salle, IL.

$\rightarrow$ Pollock, J.: 1983, 'Epistemology and Probability', Synthese 55, 231-52.

Ryan, S.: 1991, 'The Preface Paradox', Philosophical Studies 64, 293-307.

Vogel, J.: 1990, 'Are There Counterexamples to the Closure Principle?', in M. D. Roth and G. Ross (eds.), Doubting, Kluwer Academic Publishers, Dordrecht, pp. 13-27.

Department of Philosophy

West Virginia University

Morgantown, W.V. 26506-6312

USA 